of maliciously inflicting injury? There may be no serious wound or ecchymosis on the head, neck, or face of the first child referred to, any more than the other two, when medically examined outwardly, sufficient to convict of injury; but it may be found, if sought for, of greater or less extent, within. Where else is evidence of the cause of death in many newborn children to be relied on? Not, as bitherto, in the hydrostatic test; as it would appear that this is not to be required. We, therefore, are shut up to whatever state the brain and its membranes, or the heart, may be in, to decide the cause of death in the instances of new-born children suspected of having been foully dealt with. It is true, and proper to bear in mind, that the head of the child in certain kinds of labour, when extruded, may remain, from various causes (maternal and fotal) too long in such position; and, on its complete birth, may be stillborn, without the woman, or any one else, having meddled with it at all. But, on the other hand, if such is to be the law in future, that "no proof that the child was completely born alive should be required", how many may be led to bring about by secret means a child's death during its birth without fear of penalty, when early medical examination would be often able to detect the malicious injury inflicted, but for such a law.

A woman alone is seized with the pains of labour at full time, and soon bears her child alive; but, after it is born, she finds the umbilical cord twice at least round its neck, and is anxious to relieve herself and the child. In trying to remove the cord, she only causes a greater constriction of the neck, whereby the fotal respiration is the more impeded; and by the time she has managed to free the child of it, life has fled. In a case of this kind, there might be caused marks on the neck of the child, sufficient to excite suspicion against an innocent person. Another, also alone during the bearing of her child, is standing and about to get into a low bed, when a severe uterine pain comes on, by which the child is forcibly and quickly expelled, and driven against the corner of a chair or stool, causing a wound or fracture of the child's head, ending in the death of it; and the woman, although suspected, would be innocent. Another alone in labour feels as if she were to have an evacuation, and sits down on a house slop-pail with water in it; a succession of violent pains takes place; and before she gets off it, the child is not only born, but it has lost its life by being drowned. Another woman, unmarried, is taken in labour, alone; the child is found, not long afterwards, dead, with its umbilical cord insufficiently tied, which has caused the death of the child by loss of blood. On the other hand, what is to hinder a lyingin woman wickedly doing away with her new-born child from afterwards screening herself under the same states and circumstances as above described? There would be much room for conflicting medical evidence in such a case.

A case of labour, at full term, in a married woman, about 40, who had several children before, came under my care not very long ago, where an elderly female was in attendance. The child, the mother said, was living prior to labour-pains coming on, and it came by the feet. The attendant, thinking she had no more to do than to pull the child's feet and deliver the woman, continued pulling away; until the mother became alarmed, as the child was not coming so soon as she expected, and I was therefore hastily sent for ; on my arrival I found her still undelivered, but the child was now dead. The head was by me readily brought into the world. What is to be done with those unprofessional and unlearned persons who proffer their aid in such and other cases, as well as with those itinerant quack evil advisers who vend medicines secretly to cause abortion, especially in advanced pregnancy in unmarried females, occasionally with a fatal termination? Some greater restriction is certainly required to be put in force by the legislative powers of government against such persons.

Inattention to the severed and tied end of the umbilical cord seemed to have been the cause of phlegmonoid inflammation and death in two infants of different mothers, which I was lately requested to see before they died. The neglect was apparently unintentional on the part of either the mothers or attendants!

\section{REMINISCENCES OF A FOUR MONTHS' STAY WITH PROFESSOR A. VON GRAEFE IN BERLIN.}

\author{
By A. Sammlson, M.D., Manchester. \\ [Continued from $p .309$.
}

THose three days of the week, on which Von Graefe lectures in the morning-i.e., Monday, Wednesday, and Fridey -are also set apart for operating. This generally commences soon after 3 o'clock P.M., and is continued for about an hour, within which, on an average, fifteen operations are performed. Some eight or ten of the hearers regularly attending the lectures are in turn admitted to watch the operations, as well as the preceding attendance on the ambulatory patients. The remaining afternoons of the week, apparently devoted to the more collected and thorough investigation of cases, are passed in comparative seclusion; only a casual visitor being present, or some foreign colleague anxious to make the most of his limited stay at Berlin. But, on the operating-days, the number of practitioners mostly equals or exceeds that of the pupils; and, amongst the former, one or another person of high repute, or at least local celebrity, may often be met with. We had the good fortune of meeting Dr. Desmarres of Paris, Professor Rossander of Stockholm, Dr. Melchior of Copenhagen, Dr. Heymann of Dresden, etc.

The ordinary medical attendant of a patient is in many instances present to watch the operation on the latter. As Von Graefe, when in Berlin, performs but very few operations any where else but at the Clinique, the interesting spectacle is presented of a concourse of patients of each sex, belonging to the most various countries and ranks of society. Not to mention a host of counts and countesses, high functionaries and military officers, financiers, etc., we saw two children of royal birth, grand-cousins of King William of Prussia, brother and sister, operated upon in succession-the one for squint ; the other for closed pupil in the only and but very poor eye left to her. Amongst the foreign patients, the most abundant are Russians, and next in number Frenchboth, it appears, appreciated on account of their substance and liberality; but, amongst the former, the poorer classes also are most numerously represented, especially the Jews of Poland and the Baltic provinces, obviously much visited with eye-diseasequaint people with curious names, such as Rosetwig, or Gingerbread, or Mother-o'-Pearl, and often distinguished by their epizootic propensities. Perhaps this latter proclivity accounts in part for the comparatively frequent occurrence among them of an otherwise rarely seen disease-trichosis, or Plica Polonica-of which we met with three or tour examples. In some instances, when persons of high rank, especially ladies or very nervous individuals among the 
private patients, are to be submitted to an operation, the students attending are requested to withdraw for a while; otherwise little distinction is made on account of the standing of the various subjects. Time presses ; chloroformisation, for that very reason often dispensed with, absorbs precious minutes; so does the dressing, when attended to by Von Graefe himself ; lid-operations, especially blepharoplastic ones, are necessarily tedious; yet the task of the day must be performed, as postponement would soon result in an avalanche. Habituated to intercourse with persons of towering position in every possible sense, Von Graefe is ever at his ease; favoured by birth, fame, titles, and badges, which all are his in plenty, he, the observed of all observers, is civilly genial with every one; stiffness, assumption, or pedantry have no hold on him. Remarkable is his considerate bearing towards practitioners who, as often occurs, happen to be present when a former patient of their own appears among the crowd of his patients. Apologisingly he appeals, as it were, to the indulgence of the colleague, and never fails to endeavour to restore the patient to his previous adviser. Exceptionally only, a patient is operated on in his or her own room; and the whole of the operations are performed by Von Graefe's hand, except occasionally a squintoperation or an iridectomy, entrusted, under his guidance, to the junior clinical assistant, for his benefit. The patient is invariably placed on the couch ; the operator sitting, as the case may require, either before or behind him. Being slightly hypermetropic, Von Graefe sometimes arms himself with his convex glasses when a minute inspection is deemed requisite. No operation on the globe of the eye is attempted without fixing it with forceps. The distension of the palpebral aperture is effected by means of the stop wire-retractor. The head of the patient is fixed by an attendant-trusty Andreas, well known to the professor's pupils and friends all the world over, on whom this sufficiently important task has now devolved for upwards of thirteen years. And fully this time Dr. Waldau (who some years since adopted this instead of his former name of "Schuft") has been Von Graefe's assistant in operations. To the superlative skill and ingenuity which this gentleman brings to bear upon his share of the work we think that no description can do entire justice. Much may be said in praise of his ability in the devising of ingenious and more or less useful instruments, amongst which the curette, perfected by him and generally known as Schuft's spoon, was the most valuable; but his singular tact, the extraordinary quickness of perception by which he ofttimes anticipates the want of the operator, his firm and secure yet gentle touch, are qualities highly developed by such an enormous practice, and the exhibition of which it is certainly no less instructive than gratifying to witness. A short word of encouragement on his part, fitly though charily bestowed, also often goes far to tranguillise a nervous or obstreperous patient just undergoing an operation. On the other two assistants, who in turn with him have the attendance on private patients, devolves the duty of watching the operations, respectively of administering chloroform, in their own cases. It is the office of the junior clinical assistant to hold the tray of instruments, and to tender or receive them back as the moment requires. As a rule, the instrument-maker (J. G. Birck, seri., Dorotheen Strasse) habitually employed by Von Graefe is expected to be present during the operations. The nurses in attendance on the various cases are in readiness with their supplies to assist in the dressing of the patients, and to lead them back to their rooms.
Chloroform is given in less than half of the cases. In five days, we counted forty, in which it was employed. To its administration Von Graefe generally attends himself, so long as his hands are still at disposal for the purpose; but, even when deeply engaged in operating, he is ever most sensitively awake to the behaviour of the subject under chloroform, and, with delicate discrimination, directs either the continuance or the withdrawal of the anresthetic. He has never yet had to lament the loss of a patient from its influence. I have seen it at the Clinique employed in about four hundred cases; and amongst this number there was but a single one in which some momentary uneasiness was caused by the ap. pearance of the patient. In explanation, however, it must be stated that chloroform is here hardly ever administered with the intent to induce profound narcosis, except, perhaps, in those rare cases of malignant disease where the removal of bone becomes necessary. A superficial administration, and hence a small quantity, is usually found sufficient for the purpose; and a larger dose may, in fact, well be dispensed with, seeing that there are always plenty of people at hand to efficiently control the movements of the patient. Besides, there is no time either for protracted inhalation or for much delay in recovering from the effects of the anæsthetic. It is, perhaps, owing also to the small quantities given that we have but rarely seen the employment of chloroform followed by vomiting. No apparatus is used, except a cylinder of pasteboard, lined with cloth, open at both ends and tapering upwards, of about three inches' diameter at its base, which has a shallow notch for the nose. The chloroform is poured on the lining. In the appreciation of the symptoms of danger, little stress is laid on the condition of the pulse: the state of the respiratory function absorbs the attention.

We have witnessed the operative practice of ophthalmologists who certainly equal, if they do not in some respects surpass, Von Graefe, as regards delicacy of performance; but we know of none exceedin him in the precision with which he establishes his indications prior to the manual business of operating. Morbid specimens of interest accruing from operations are generally despatched for examination to Professor Virchow, or his distinguished assistant, Dr. Kühne. The instruments are restored to the careful custody of Dr. Depaubourg, the inspector. Von Graefe, who, in the short intervals between operations, was now and then seen to be preoccupied, when he appears to revolve in his mind the phases of some operative proceeding just carried out, at once attends to the insertion of important observations in his journals, more especially the entering of cataract-operations in the book of cataracts-a re. cord solemnly kept and deservedly valued, in which a special corner is conscientiously set apart for mishaps. Having, lastly, fulfilled a duty responsible enough not to be delegated-i. e., dictated a number of certificates, ever lucid and exhaustive, little masterpieces in conception and style-he with. draws to the wards, to finish his round of visits, when a day's work as trying as interesting is once more brought to a close.

The teaching arrangements at Von Graefe's Clinique, apart from the practical lessons implied in the afternoon work which we have just reviewed, appear to call for a separate notice. Here we find, as it were, a little university of ophthalmology established. Dr. Waldau teaches the ophthalmic operations in a course of twelve lessons, giving, we believe, four such courses in each of the two academical divisions of the year. Dr. Schelske (lecturer at the University, and known as the author of several elaborate phy- 
siological essays), the scientific assistant, as we shall call him, whose office was but recently, after a tenure of some years, vacated by the eminent pathological anatomist, Professor Schweigger, gives three different courses of instruction-one on ophthalmoscopy, another on the diseases of refraction and accommodation, and a third on the pathological anatomy of the eye. Professor von Graefe himself discourses on the diseases of the eye, as we have stated, three times a week, from ten to eleven o'clock in the morning. There were, on an average, from fifty to sixty hearers attending-among them always a number of qualified medical men. They are seated on chairs in two double rows, confronting each other, and leaving a passage between them for the patients presented, and particularly for the lecturer, who seldom occupies a seat, and ever and anon repairs to the black board, which, though moveable, rivals indeed the most stable of fixtures : it is his most cherished instrument of instruction, in the nse of which, whether lecturing, or conversing, or pausing from an operation, he is untiring, and the convenience of which he is very apt to suggest to any party conveying or seeking some information. The cases to be produced are, on the day preceding a lecture, selected by Von Graefe himself, or more frequently, under his direction, summoned by the junior clinieal assistant; who also, seconded by one of the male attendants, controls their movements to and from the lecture-room. A few minutes before the commencement of his lecture the professor spends in glancing at some of the cases in the anteroom. Some four or five of those among the students who believe themselves to be sufficiently advanced not to be listeners only, examine the cases previously to the lecture, in order to prepare themselves for the impending interrogatory. The lecturer does not profess within a given period to exhaust the whole subject of ophthalmology; his lectures are clinical in the received sense of the term. As cases emerge, or a series of cases, invested with practical interest, they are made the substratum of instruction. There is, however, scarcely anything of importance missed during the term; and whatever is taken up is certain to be exhaustively treated. The number of cases dwelt on in this manner are from two to five in the course of a lecture, towards the end of which as many or more are cursorily dealt with. Not unfrequently, the suggestion or request of a friend is sufficient for a subject to be made the item of discourse. The delivery of the lecturer is spirited in the highest degree, signalised by the most perfect ease and freedom, sometimes perhaps too rapid, though ever elevated in style. The tone is very frequently colloquial, and only becomes more measured when the teacher rises as it were with his subject-e.g., when he comes to treat on such chapters as paralytic disease, or the disorders of accommodation and refraction, or, especially, muscular asthenopia. We shall long harbour the impression we received when, having descanted in the most perspicuous strain on the last named very intricate and most interesting subject, he wound up his remarks by reminding us that the subject was one of the highest practical importance, and that the fathoming of it did honour to the human understanding. To my mind, this succinct peroration, most objectively pronounced as it was, enbodied the text of a panegyric such as in our day but few men might more rightfully claim than the speaker. We should, however, find it difficult to decide where his teaching was more instructive and suggestive; whether when he spoke on amblyopia, or when on the consistency of cataract, or, again, on the various forms of conjunctivitis and keratitis. We have once more been in the position lately of listening to teachers of great and deserved renown; but, thankful as we feel for many a valuable lesson, we did not fall in with any one who "had the elements so mixed in him".

[To be continued.]

ErRata. The following corrections are required in that part of Dr. Samelson's paper which appeared in the Journal of March 24th.

Page 306, col. Ir, line 28 from bottom, for " 10.20 ", read " $10.30 "$ ".

Page 306, col. Ir, line 8 from bottom, omit "many".

Page 308, col. II, line 15 from bottom, for "mentioned above", read "here mentioned".

Page 309, col. I, line 6 from bottom, for "invariably", read "invincibly".

\section{ON THE TREATMENT OF STRABISMUS WITHOUT OPERATION.}

By C. Houthousr, Esq., Surgeon to the Westminster Hospital, and to the Surrey Ophthalmic

Hospital, etc.

[Continued from page 252.]

Case Iv. Double Convergent Strabismus of the Left Eyje to one Line, of the Right to three and a half Lines, from Paralysis of the Left External Rectus Muscle. Mary D., aged 52, married, came under my care at the Surrey Ophthalmic Hospital on August 17th, 1865 , for double convergent strabismus, which had made its appearance eight days previously, having been preceded by what seems to have been a slight conjunctivitis in consequence of cold; the eye being "bloodshot", slightly watery, and affected with "a pricking sensation", and the lids "gummy" in the morning. Two days after this inflammation had subsided, the patient was seized suddenly, in the middle of the day, with a severe shooting pain in the left eyeball, extending over the left side of the forehead and head and the upper part of the nose on the same side, together with much giddiness, confusion of vision, and diplopia, so that she had been afraid to trust herself to go about alone ever since.

Condition on Application. The above symptoms were still present with scarcely diminished severity. The eyeball was very tender on pressure, and its movements were painful ; but its tension was normal, and there was no vascularity of the sclerotic or conjunctiva. The pain over the forehead and head followed exactly the course of the supraorbital and supratrochlear nerves, pressure on which, at their points of exit from the orbit, caused much suffering. On examining the movements of the eje, the right being covered, they were found to be limited in the outward directions; $i$. e., the cornea could be brought exactly to a central position between the canthi, but not beyond; and the diagonal movements in an outward direction were defective. On the patient trying to look outwards, no action of the oblique muscles could be detected. The power of inverting the eye was perfect. On attempting to grasp a pen held a little to her left, she always clutched at it as if it were still more to her left than it really was. The pupil was of normal size, and responded readily to the stimulus of light. The eye was presbyopic to $\frac{1}{14}$; otherwise its vision was good-indeed, rather better than that of the right eye; for, whereas the latter had an acuity of vision of only $\frac{2}{3}$, the left was normal. The vision of the right eye was $\frac{20}{30}$, and with 30 lens, $\frac{20}{2}$, and that of the left eye $\frac{20}{20}$; so that the defect of sight of the right eye was due to hypermetropia. On closing the paralysed eye, the movements of the right eye and of its pupil were found to be perfect. 